$\checkmark$ Research Square

\title{
Navigating toward TB elimination: the California perspective.
}

Adam Readhead ( $\square$ adam.readhead@cdph.ca.gov)

University of California, Los Angeles https://orcid.org/0000-0003-3186-9027

Jennifer Flood

California Department of Public Health

Pennan Barry

California Department of Public Health

\section{Research article}

Keywords: tuberculosis, health care utilization, health care access, elimination, country of birth

Posted Date: September 7th, 2019

DOI: https://doi.org/10.21203/rs.2.14029/v1

License: (1) This work is licensed under a Creative Commons Attribution 4.0 International License. Read Full License 


\section{Abstract}

Background The California tuberculosis (TB) elimination plan calls for testing more than ten million atrisk Californians and treating two million infected with tuberculosis. Detailed knowledge about the at-risk population and the healthcare providers who serve them is crucial to further reduction of the TB burden in the state.

Methods We used data from the population-based 2014-2017 California Health Interview Survey (CHIS) to examine demography, healthcare access and utilization, and language use, focusing on countries of birth with the highest number of TB cases in California.

Results The six top countries of birth accounting for $62 \%$ of TB cases were Mexico, United States (U.S.), Philippines, Vietnam, China and India. CHIS data showed that poverty was highest among Mexican-born persons, 56\% (Cl: 54-58) and lowest among Indian-born persons, 9\% (Cl: 5-13). Report of recent doctor's visit was highest among persons born in the Philippines, $84 \%$ (Cl: 80-89) and lowest among Chinese-born persons, $70 \%$ (Cl: 63-76). Persons born in Mexico were more likely to report community clinics as their usual source of care than persons born in China, Vietnam or the Philippines. Among 18-64 year olds, $27 \%$ (Cl: 25-30) of persons born in Mexico reported being uninsured in contrast with $3 \%$ (Cl: 1-5) of persons born in India. Of adults with a medical visit in a non-English language, 96\% (Cl: 96-97) were non-U.S.-born, but only $42 \%$ (Cl: 40-44) of non-U.S.-born persons had a visit in a non-English language.

Discussion Patterns of demography, healthcare utilization and language use were notably different by country of birth. These differences should be considered when planning outreach to specific providers, clinic systems, insurers and communities for TB prevention and case-finding.

\section{Background}

Tuberculosis (TB) is the number one infectious disease killer worldwide causing 1.6 million deaths and ten million new cases of disease in 2018 [1]. In the United States (U.S.), substantial reductions in TB have been achieved. The national case rate has declined from 52.6 per 100,000 in 1953 to 2.8 per 100,000 in $2018[2,3]$. Yet gains against the disease have slowed in recent years. The national case rate declined less than 1\% from 2017 to 2018.

How, then, do we make progress against TB in the U.S.? Several mathematical models show that meaningful reduction in TB burden will not be achieved without a significant effort at TB prevention in the form of targeted testing and treatment of persons at risk for latent TB infection $[4,5]$. Separate evidence 
suggests more than $85 \%$ of cases result from undiagnosed and untreated TB infection, further emphasizing that targeted testing and treatment could prevent a substantial proportion of TB cases [6].

In California, where more than $20 \%$ of TB cases nationwide occur and more than two million people are infected with TB, the California Department of Public Health has put forward an ambitious TB elimination plan $[3,7,8]$. The plan calls for identifying and treating Californians infected with tuberculosis as recommended by the United States Preventive Services Task Force [9]. It includes an effort to engage providers to increase knowledge and use of TB tests and treatment and a campaign to increase public awareness about TB and public demand for TB testing and treatment.

One specific barrier to implementing TB prevention in large health systems is that country of birth, the most important risk factor for TB, is often not captured in the electronic medical record (EMR). Without country of birth data, technology available in the EMR, such as prompts or reflex testing, cannot be used to promote TB testing among these at-risk groups. In lieu of country of birth data, preferred language, which is often populated in EMR data, may be useful as a proxy for country of birth.

To plan these activities and address known barriers, we sought to describe the demography, healthcare utilization and access and language use of groups at risk for TB in California using a large-scale, population-based health survey.

\section{Methods}

Data were drawn from the California Health Interview survey (CHIS) for survey years 2014-2017 $(n=82,758)[10]$. CHIS is an annual population-based telephone survey of California residents that employs both landline and cellphone random digit dialing with oversampling of Korean and Vietnamese persons [11]. Interviews were conducted in English, Spanish, Mandarin, Cantonese, Vietnamese, Korean 
and Tagalog. Details of the CHIS questionnaire have been published previously [12]. Data were based on respondent self-report and analysis was limited to persons 18 years and older. Educational attainment was estimated among persons 25 years old and older.

We calculated survey proportions and $95 \%$ confidence intervals $(\mathrm{Cl})$ stratified by country of birth, focusing on those countries with the highest number of TB cases in California. Because previous studies have shown the burden of TB falls disproportionately on non-U.S.-born persons, we focused on six countries that accounted for $62 \%$ of all cases in California during 2016-2017 [13, 14]. Poverty was defined as less than $139 \%$ of the federal poverty level, to align with health insurance premium subsidy levels set by the Affordable Care Act. High deductible plans were defined as those plans with an annual deductible of more than $\$ 1,000$. Delayed or forgone medical care and delayed or forgone medicine were defined as events occurring in the last 12 months; these questions were asked of persons with health insurance in the last 12 months. Treated unfairly when getting medical care was defined as being treated unfairly sometimes or often when getting medical care over lifetime. Racial or ethnic discrimination was defined as responding yes to the question "was there ever a time when you would have gotten better medical care if you had belonged to a different race or ethnic group?" Usual source of care was condensed from seven categories to three as follows: doctor's office, $\mathrm{HMO}$ or Kaiser were grouped as doctor's office; community clinic or hospital and government clinical or hospital were grouped as community/government clinic/hospital; no usual place, emergency room, urgent care, other place, and no one place were grouped as no usual source. Language at medical visit was defined as the language spoken by doctor at last medical visit excluding those who had difficulty communicating with their doctor $(<5 \%)$ or without a medical visit in last two years. Respondents who did not answer this question but had a medical visit in the last two years and conducted their survey in English were categorized as speaking English at the medical visit. Data on unfair treatment when getting medical care, perceived racial of ethnic discrimination, and diabetes (non-gestational) were limited to 2015-2017 because these questions were not included in the 2014 survey. We adjusted the following variables by age because of age-related differences: doctor's visit in the last 12 months, overall health, smoking and diabetes. We used the 2017 US Census annual estimate of population by age groups for California as the standard population for age-adjustment [15]. Survey proportions based on less than three respondents or 500 weighted 
respondents were suppressed per California Department of Public Health guidelines for CHIS use. Analysis was done in SAS 9.4. This project was deemed not research by the California Health and Human Services Agency's Committee for the Protection of Human Subjects (Federal-wide Assurance \#00000681).

\section{Results}

\section{Demographic and socioeconomic factors}

Demographic and socioeconomic factors of the populations at risk for TB including sex, age, length of residency in the U.S., education, poverty and English language proficiency differed by country of birth (Table 1). For example, the proportion of females by country of birth ranged from $60 \%$ (Cl: 52-68) among Chinese-born persons to 43\% (Cl: 34-51) among Indian-born persons. The proportion of 18-29 year olds among US-born was $27 \%$ (Cl: 27-27) with far lower proportions among persons born outside the US, ranging from 8\% (Cl: 4-11) among those born in Vietnam to 19\% (Cl: 14-24) among those born in China. Close to three-quarters of persons born in Vietnam or Mexico reported residing in the U.S. for 16 years or more compared with two-thirds of persons born in the Philippines and half of persons born in China or India.

There were also substantial differences in educational attainment by country of birth. Of persons born in Vietnam, 55\% (Cl: 48-63) had a high school education or less. Among persons born in Mexico, that estimate was 83\% (Cl: 81-85). The proportion with a high school education or less was 13\% (Cl: 8-19) among persons born in the Philippines. Poverty followed similar patterns to educational attainment, with some notable differences. Among persons born in Mexico or Vietnam, 56\% (Cl: 54-58) and 47\% (Cl: 3755) respectively lived in poverty. In contrast, $19 \%(\mathrm{Cl}$ : 18-20) and 9\% (Cl: 5-13) of persons born in the U.S. or India lived in poverty. 
Patterns of healthcare insurance were also notably different (Table 2). The proportion of 18-64 year olds who were uninsured ranged from 27\% (Cl: 25-30) among persons born in Mexico to 3\% (Cl: 1-7) among persons born in India. Among persons 65 years old and older, the proportion who reported both Medicare and Medi-Cal coverage ranged from 14\% (Cl: 12-16) among U.S.-born to 72\% (Cl: 59-84) among persons born in Vietnam. More than half of Indian-born persons, 51\% (Cl: 39-62), reported high deductible health insurance plans in contrast to a third of US-born persons who reported the same, 33\% (Cl: 32-34).

\section{Healthcare utilization and barriers to care}

The proportion of persons reporting visiting a doctor in the last 12 months differed by country of birth, even after age adjustment (Table 2). Report of age-adjusted recent doctor's visit was highest among persons born in the Philippines, 84\% (Cl: 80-89) and lowest among Chinese-born persons, 70\% (Cl: 63-76). Age-adjusted recent doctor's visit among persons born in the U.S. was 83\% (Cl: 83-84).

There was also a substantial difference in usual source of care by country of birth (Table 2). The proportion reporting a doctor's office as usual source of care was highest among Vietnamese-born persons at 73\% (Cl: 66-81) and lowest among Mexican-born persons, 31\% (Cl: 24-34). The proportion reporting no usual source of care was highest among Mexican-born persons at $28 \%$ (Cl: 26-30) and lowest among Indian-born persons at 11\% (Cl: 6-15).

On the basis of responses to survey questions, the proportion of persons experiencing barriers to care was low. Small proportions of these groups had delayed or forgone medicine or medical care. Whereas 11\% (Cl: 11-12) of U.S.-born persons had delayed or forgone medicine, 4\% (Cl: 2-7) of Chinese-born persons had done the same. Similarly, $14 \%$ (14\%-15\%) of U.S.-born persons had delayed or forgone medical care, whereas 7\% (4-10) of Chinese-born persons had done the same. 
With regard to racial discrimination and unfair treatment, the proportion reporting these barriers was low. Of U.S.-born persons, $10 \%$ (Cl: 9-11) reported being treated unfairly sometimes or often when getting medical care. Of persons born Mexico, 14\% (Cl: 11-16) reported the same. In contrast, of persons born in China 7\% (Cl: 3-11) reported this. Low proportions reported that they would have gotten better care if a different race/ethnicity. Less than 10\% reported having a hard time understanding the doctor at last visit with the highest proportion among Mexican-born persons at 7\% (Cl: 5-8) and Chinese-born persons 6\% (Cl: 2-9). For comparison, the estimate was 3\% (Cl: 2-3) for U.S.-born persons.

\section{Overall Health and Risk factors for TB reactivation}

Age-adjusted overall health differed widely by country of birth (Table 2). Among U.S.-born, $54 \%$ (Cl: $52-55$ ) reported very good or excellent health. Lower proportions of good or excellent health were reported by persons born in Mexico or in Vietnam: 26\% (Cl: 24-28) and 29\% (Cl: 21-38). The highest proportion with very good or excellent health was among persons born in India at $62 \%(\mathrm{Cl}: 52-71)$.

Current smoking was highest among persons born in Vietnam 11\% (Cl: 6-17) though the confidence interval was wide. Persons born in Mexico or the Philippines reported high proportions of former smoking, 18\% (Cl: 16-20) and 19\% (Cl: 14-23) respectively. Of persons born in the U.S., 24\% (Cl: 23-25) reported former smoking. Former smoking was lower among persons born in Vietnam, China or India, 8\% (Cl: 412), 8\% (Cl: 5-12) and 10\% (Cl: 6-15) respectively.

Of persons born in Mexico or the Philippines, 17\% (Cl: 14-19) and 17\% (Cl: 12-23) reported diabetes respectively (age-adjusted). Diabetes proportions were lower among persons born in Vietnam, China and India, similar to the level observed among the U.S.-born, 8\% (Cl: 8-9).

Language at medical visit and at home 
Of adults with a medical visit in a non-English language, 96\% (Cl: 96-97) were non-U.S.-born (Table 4). This pattern was consistent across languages (Table 3). Of persons with visits in Spanish, 78\% (Cl: 7581) were born in Mexico and 19\% (Cl: 12-21) elsewhere outside the U.S. Of persons with visits in Tagalog, 96\% (Cl: 88-100) were born in the Philippines. Of persons with visits in Vietnamese, 96\% (Cl: 92-100) were born in Vietnam. Proportion non-U.S.-born for visits in Mandarin, Cantonese or an Asian Indian language were similar.

Of non-U.S.-born, 42\% (Cl: 40-44) had medical visits in a non-English language. This proportion varied across countries of birth. Among persons born in Mexico or Vietnam, 60\% (Cl: 58-63) and 55\% (Cl: 46-63) had visits in Spanish or Vietnamese respectively. Similar results were found for persons born in China. In contrast, among persons born in India or the Philippines, 96\% (Cl: 94-99) and 91\% (Cl: 87-95) had a visit in English. Of U.S.-born, 0.7\% (Cl: 0.5-0.9) had visits in a non-English language.

Of adults who did not speak English at home, $89 \%$ (Cl: 88-90) were non-U.S.-born. Among non-U.S.-born, 43\% (Cl: 41-44) did not speak English at home.

The proportion of persons residing in households in which no English was spoken ranged widely by country of birth (Table 1). Of persons born in the Philippines, 9\% (Cl: 6-12) spoke only Tagalog at home and, of persons born in India, 14\% (Cl: 9-19) spoke only an Asian Indian language at home. In contrast, $53 \%$ (Cl: 46-61) of persons born in Vietnam spoke only Vietnamese at home and 50\% (Cl: 47-52) of persons born in Mexico spoke only Spanish at home. English proficiency estimates followed similar patterns with 53\% (Cl: 45-61) of Vietnamese-born persons and 67\% (Cl: 65-69) of Mexican-born persons reporting speaking English not well or not at all. Among persons born in the Philippines or in India, 7\% (Cl: 3-12) and 1\% (Cl: 0-3) reported speaking English not well or not at all although these estimates are statistically unstable.

\section{Discussion}


As California transitions from TB control activities focused on finding and treating active TB disease to TB prevention activities requiring latent tuberculosis infection (LTBI) testing and treatment among populations at risk for TB, detailed knowledge about the population of the ten million persons in California born outside the U.S. is crucial. Our analysis of CHIS data points out several important differences in demography, healthcare access and utilization, and language use among populations by country of birth. These differences present opportunities and signal potential pitfalls for planning outreach to specific providers, clinic systems, insurers and communities.

First, and most encouragingly, most persons at risk for TB had health insurance and were engaged with medical care. Barriers to healthcare access and utilization, such as cost and racial/ethnic discrimination, affected less than one in ten persons. This means that, with the notable exceptions of persons experiencing homelessness and one quarter of persons born in Mexico who are uninsured, the hurdle of getting at-risk populations into care has largely been met. Future efforts should focus on encouraging atrisk patients to ask for TB testing and treatment and aiding providers in their efforts to test and treat persons already in care. Since a large proportion of at-risk populations are in care, public awareness campaigns could consider intervening with patients at or around the point of care.

Second, usual source of care for the groups at risk was notably different. Persons born in Mexico were more likely to use community or government facilities or to have no usual source of care than other atrisk populations. Although community and government providers are natural partners for public health programs, persons born in countries with the highest TB rates like Vietnam and the Philippines are less likely to use these providers. While more than a third of Vietnamese-born 18-64 year olds and one-fifth of those over 65 years old had public insurance, less than one in ten used government or community facilities. Overall, efforts to reach at risk populations should not focus solely on public healthcare systems and publically funded clinics but must engage both public and private healthcare systems. In addition, health insurance coverage alone cannot predict the usual source of care in these at-risk populations. This is important to keep in mind when drawing conclusions for populations in which data on usual source of care is not available. 
Third, the prevalences of risk factors for the progression of latent TB infection to TB disease varied widely among the populations examined. Self-reported diabetes and, similarly, former smoking among Philippines-born and Mexican-born persons was more than double the rates for persons born in other countries. The prevalence of these risk factors among populations already at risk for TB provides opportunities for engagement with providers who may not currently think about TB even when seeing persons at risk for the disease. One engagement strategy could be using a common comorbidity such as diabetes as an entry point for provider education about TB. It also highlights an opportunity to collaborate with organizations which focus on these comorbidities. The dual intervention of smoking cessation and latent TB infection targeted testing and treatment could have a powerful effect by averting costly and deadly disease in key groups.

Fourth, there were prominent differences in the demography of at-risk populations. Persons born in Mexico or Vietnam were more likely to be long-term residents of the U.S., have lower education attainment, and higher poverty levels in comparison to persons born in the Philippines, China or India. Roughly, one-fifth of U.S.-born persons lived in poverty whereas one quarter to one half of persons born in selected countries were impoverished, with the exception of persons born in India. In addition, persons born in Mexico, Vietnam or China were more likely not to speak English at medical visit or at home than persons born in India or the Philippines. This information, especially language use and educational attainment, would have immediate, practical use in tailoring public-facing campaigns. For example, this information could guide what languages and reading levels educational materials are offered in. A major barrier to implementing TB prevention activities in large health systems is that country of birth, the most important risk factor for latent infection, is often not captured in the EMR. However, preferred or primary language is often populated in EMR data. We examined whether language used at medical visit could be used as a proxy for country of birth, assuming that language used at medical visit is concordant with preferred language as noted in the EMR. 
Our results show that non-English language at medical visit was an excellent proxy for non-U.S. birth, but identified only half of all non-U.S.-born persons. Thus, preferred language, as noted in EMR, may be suitable as a starting point for identifying high-risk subgroups. Still, EMRs should be modified to collect country of birth, without which a large portion of the at-risk population could be missed. Language used at medical visit and at home were roughly concordant which provides an opportunity to use language at home when language at medical visit is not available. Non-English speaking persons could be at increased risk for TB compared with other persons from the same country. Non-U.S.-born persons with low educational attainment are at increased risk of TB and, from this analysis, we see non-U.S.-born persons with low educational attainment are more likely not to speak English [16, 17].

This analysis has many strengths including population-based data and large sample size, but it also has limitations. Most importantly, these results are most useful if, within country of birth strata, persons with LTBI have similar health care access and utilization patterns as those without LTBI. This might not be the case. Important at-risk populations, such as persons experiencing homelessness, were less likely to be surveyed and presumably have different healthcare access and utilization patterns. Due to questionnaire construction, language used by patient at medical visit could not be directly assessed. Language used by doctor at medical visit was used instead. Also, geographic differences, including differences between Northern and Southern California and between urban and rural settings, were not explored.

We envision efforts to engage populations at risk for TB and the providers who serve them will be multifaceted and multi-sectorial, and should be tailored to specific communities and providers. Other states could tailor their own TB prevention efforts by conducting similar analyses using data from the American Community Survey and state-level health surveys. The information presented here can support this tailored approach and represent another step towards TB elimination in California and the U.S.

\section{Declarations}

Ethics approval and consent to participate 
This study was deemed exempt by the California Office of Statewide Health Planning and Development Committee for the Protection of Human Subjects. This decision was issued under the California Health and Human Services Agency's Federalwide Assurance \#00000681.

\section{Consent for publication}

Not Applicable

Availability of data and material

Data analyzed in this project are available by application to the University of California Los Angeles Center for Health Policy Research at https://healthpolicy.ucla.edu/chis/data/Pages/GetCHISData.aspx.

Competing interests

Authors have no competing interests to report.

\section{Funding}

This analysis was performed to fulfill the public health program goal of analyzing and interpreting data to inform and improve TB prevention and control efforts; no specific funding stream was used to perform this work.

\section{Authors' contributions}

Adam Readhead and Pennan Barry designed the study, interpreted the results and revised the manuscript. Adam analyzed the data and drafted the manuscript. 
Acknowledgements

The authors would like to acknowledge Alex Golden, David Dauphine, Jennifer Rico and staff at the UCLA Center for Health Policy Research for their assistance in this project.

\section{Tables}

EXHIBIT 1 (table)

Caption: Demographic Characteristics and TB Burden by Country of Birth, California 2014-2017 


\begin{tabular}{llllll} 
Philippines & Vietnam & India & China & Mexico & United \\
$\%(95 \% \mathrm{Cl})$ & $\%(95 \%$ & $\%(95 \%$ & $\%(95 \%$ & $\%(95 \%$ & States \\
& $\mathrm{Cl})$ & $\mathrm{Cl})$ & $\mathrm{Cl})$ & $\mathrm{Cl})$ & $\%(95 \% \mathrm{Cl})$ \\
\hline
\end{tabular}

Sex

\begin{tabular}{lllllll} 
Female & $58(51-64)$ & $54(45-$ & $43(34-$ & $60(52-$ & $51(49-$ & $51(50-51)$ \\
& & $62)$ & $51)$ & $68)$ & $52)$ & \\
\hline Male & $42(36-49)$ & $46(38-$ & $57(49-$ & $40(32-$ & $49(48-$ & $49(49-50)$ \\
& & $55)$ & $66)$ & $48)$ & $51)$ &
\end{tabular}

\section{Age}

$18-29$

$17(11-22) \quad 8(4-11)$

30-39

$8(4-11)$

$19(12-$

19 (14-

$11(9-12) \quad 27(27-27)$

26)

24)

$12(8-16) \quad 14(9-20)$

$29(21-$

19 (13-

$23(21-\quad 17(16-17)$

40-49

$22(16-28) \quad 28(20-$

37)

24)

25)

$50-59+20$

50-59

$18(14-23)$

32)

24 (18-

$29(27-\quad 13(13-14)$

36)

29)

31)

$60-69$

$80+$

$10(7-14)$

24)

$17(13-22) \quad 18(11$

$12(6-18)$

$13(7-19)$

$20(18-\quad 16(15-16)$

22)

25)

$13(8-17)$

$12(10$

$14(14-15)$

$11(6-15)$

$9(5-12)$

13)

$4(2-6)$

$3(1-5)^{\star}$

$5(2-9)^{\star}$

$8(4-13)$

$4(3-5)$

$8(8-9)$

$(0-3)^{\star}$

$5(2-7)$

$1(1-2)$

$5(5-5)$

Years in the US

\begin{tabular}{|c|c|c|c|c|c|}
\hline $0-5$ & $11(6-15)$ & $7(3-11)$ & $\begin{array}{l}21(14- \\
29)\end{array}$ & $\begin{array}{l}19(14- \\
25)\end{array}$ & $4(3-5)$ \\
\hline 6-10 & $12(8-16)$ & $12(6-19)$ & $13(7-19)$ & $\begin{array}{l}16(10- \\
21)\end{array}$ & $8(7-10)$ \\
\hline $11-15$ & $12(8-17)$ & $7(4-11)$ & $\begin{array}{l}16(10- \\
23)\end{array}$ & $12(8-16)$ & $\begin{array}{l}14(12- \\
15)\end{array}$ \\
\hline $16+$ & 65 (59-70) & $\begin{array}{l}73(64- \\
81)\end{array}$ & $\begin{array}{l}49(41- \\
57)\end{array}$ & $\begin{array}{l}53(46- \\
60)\end{array}$ & $\begin{array}{l}74(72- \\
76)\end{array}$ \\
\hline
\end{tabular}

Educational Attainment (of 25 years old and older)

High school/HS equivalent or less

\begin{tabular}{llllll}
$13(8-19)$ & $\begin{array}{l}55(48- \\
63)\end{array}$ & $4(1-7)^{\star}$ & $\begin{array}{l}30(24- \\
35)\end{array}$ & $\begin{array}{l}83(81- \\
85)\end{array}$ & $27(26-28)$ \\
\hline $23(17-29)$ & $10(7-14)$ & $5(1-9)^{\star}$ & $7(4-10)$ & $9(8-10)$ & $28(27-29)$ \\
$64(57-71)$ & $34(25-$ & $91(87-$ & $64(57-$ & $8(7-9)$ & $45(44-46)$ \\
& $43)$ & $95)$ & $70)$ & & \\
& & & & &
\end{tabular}

Poverty Level

0-138\% FPL

$26(20-32) \quad 47(39-\quad 9(5-13)$

29 (23-

56 (54- $19(18-20)$

55)

35)

58)

$139 \%-249 \% \mathrm{FPL}$

$18(14-23) \quad 16(11-\quad 8(4-13) \quad 14(9-18) \quad 26(24-\quad 16(15-17)$

21)

28)

$250 \%-399 \% \mathrm{FPL}$

$18(13-22)$

$10(6-14)$

$11(10-$

$18(17-19)$

$400 \%+F P L$

$38(32-45) \quad 27(19-\quad 68(60-\quad 42(35-\quad 7(5-8)$

$47(46-48)$

Page $14 / 20$ 


\begin{tabular}{|c|c|c|c|c|c|c|}
\hline \multicolumn{7}{|l|}{ Language spoken at home } \\
\hline English only & $22(17-28)$ & $7(1-12)^{\star}$ & $9(5-13)$ & $7(4-10)$ & $2(1-3)$ & \\
\hline Language of country of birth and English & $59(54-65)$ & $\begin{array}{l}30(22- \\
37)\end{array}$ & $\begin{array}{l}70(62- \\
78)\end{array}$ & $\begin{array}{l}34(28- \\
41)\end{array}$ & $\begin{array}{l}47(44- \\
49)\end{array}$ & \\
\hline $\begin{array}{l}\text { Other including multiple non-English } \\
\text { languages }\end{array}$ & $9(6-13)$ & $11(6-16)$ & $7(3-11)^{*}$ & $12(7-18)$ & $2(1-2)$ & \\
\hline Language of country of birth only & $9(6-12)$ & $\begin{array}{l}53(45- \\
61)\end{array}$ & $14(9-19)$ & $\begin{array}{l}46(39- \\
53)\end{array}$ & $\begin{array}{l}50(47- \\
52)\end{array}$ & \\
\hline \multicolumn{7}{|l|}{ English language proficiency } \\
\hline Speaks English only & $22(17-28)$ & $7(1-12)^{\star}$ & $9(5-13)$ & $7(4-10)$ & $2(1-3)$ & $77(76-78)$ \\
\hline Very well/Well & $71(64-77)$ & $\begin{array}{l}40(32- \\
48)\end{array}$ & $\begin{array}{l}89(85- \\
94)\end{array}$ & $\begin{array}{l}54(47- \\
60)\end{array}$ & $\begin{array}{l}31(29- \\
33)\end{array}$ & $23(22-24)$ \\
\hline Not well/Not at all & $7(3-12)^{\star}$ & $\begin{array}{l}53(45- \\
61) \\
\end{array}$ & $1(0-3)^{\star}$ & $\begin{array}{l}39(33- \\
45)\end{array}$ & $\begin{array}{l}67(65- \\
69) \\
\end{array}$ & $1(0-1)$ \\
\hline \multicolumn{7}{|l|}{ TB Burden } \\
\hline $\begin{array}{l}\text { Incidence of TB disease per 100,000 person- } \\
\text { years }\end{array}$ & 45 & 41 & 25 & 23 & 10 & 1 \\
\hline Proportion of overall TB cases & 18 & 10 & 5 & 7 & 21 & 19 \\
\hline
\end{tabular}

Source: California Health Interview Survey, 2014-2017

Notes: * Statistically unstable - Coefficient of Variation $>0.3$

EXHIBIT 2 (table)

Caption: Healthcare Access and Utilization by Country of Birth, California 2014-2017 


\begin{tabular}{|c|c|c|c|c|c|c|}
\hline & Philippines & Vietnam & China & India & Mexico & United States \\
\hline \multicolumn{7}{|l|}{ Health insurance (18-64) } \\
\hline Employment-Based / & $63(56-71)$ & $54(44-64)$ & $70(64-76)$ & $88(82-93)$ & $32(30-34)$ & $65(64-66)$ \\
\hline \multicolumn{7}{|l|}{ Privately Purchased } \\
\hline Medi-Cal/ Medicare/ Other Public & $24(17-32)$ & $34(24-44)$ & $19(13-24)$ & $10(4-15)$ & $41(38-44)$ & $26(25-27)$ \\
\hline Uninsured & $12(8-17)$ & $12(6-17)$ & $11(7-15)$ & $3(1-5)^{\star}$ & $27(25-30)$ & $9(8-9)$ \\
\hline \multicolumn{7}{|l|}{ Health insurance $(65+)$} \\
\hline Medicare + Medi-Cal & $37(27-47)$ & $72(59-84)$ & $37(22-53)$ & $17(0-38)^{\star}$ & $50(44-56)$ & $14(12-16)$ \\
\hline Medicare + Other & $48(37-59)$ & $20(10-30)$ & $53(37-69)$ & $60(38-81)$ & $32(26-38)$ & $75(73-77)$ \\
\hline Medicare Only, Other Only And Uninsured & $15(6-23)^{\star}$ & $8(0-17)^{\star}$ & $10(3-17)^{\star}$ & $23(5-41)^{\star}$ & $18(13-23)$ & $11(10-12)$ \\
\hline $\begin{array}{l}\text { High deductible } \\
\text { (of employer/private insured) }\end{array}$ & $38(30-47)$ & $43(29-58)$ & $46(35-58)$ & $51(39-62)$ & $39(35-42)$ & $33(32-34)$ \\
\hline \multicolumn{7}{|l|}{ Usual source of care } \\
\hline Doctor's Office & $55(48-63)$ & $73(66-81)$ & $55(49-62)$ & $61(53-69)$ & $31(28-34)$ & $65(64-67)$ \\
\hline Community/government clinic or hospital & $29(23-36)$ & $7(4-10)$ & $27(20-33)$ & $28(20-36)$ & $41(38-45)$ & $19(18-20)$ \\
\hline No Usual Source & $15(11-19)$ & $19(13-26)$ & $18(13-23)$ & $11(6-15)$ & $28(26-30)$ & $15(14-16)$ \\
\hline Visited doctor in last 12 months $\S$ & $84(80-89)$ & $76(67-85)$ & $70(63-76)$ & $82(76-88)$ & $73(71-75)$ & $83(83-84)$ \\
\hline Hard time understanding doctor at last visit & $1(0-3)^{\star}$ & $6(2-10)^{*}$ & $6(3-9)$ & $\ddagger$ & $7(5-8)$ & $3(2-3)$ \\
\hline Delayed or forgone prescription drugs & $7(4-11)$ & $4(1-7)^{\star}$ & $4(2-7)$ & $6(0-13)^{\star}$ & $9(8-11)$ & $11(11-12)$ \\
\hline Delayed or forgone medical care & $7(4-10)$ & $7(2-12)^{\star}$ & $7(4-10)$ & $8(4-12)$ & $10(9-11)$ & $14(14-15)$ \\
\hline Treated unfairly when getting medical care & $9(5-13)$ & $11(5-16)$ & $7(3-11)$ & $11(3-19)^{\star}$ & $14(11-17)$ & $10(10-11)$ \\
\hline Racial or ethnic discriminationt & $2(0-4)^{\star}$ & $6(2-10)^{\star}$ & $8(2-13)^{\star}$ & $7(0-14)^{\star}$ & $6(5-8)$ & $4(4-5)$ \\
\hline Excellent/very good overall health $\S$ & $52(46-58)$ & $29(21-38)$ & $46(39-53)$ & $62(52-71)$ & $26(24-28)$ & $54(52-55)$ \\
\hline \multicolumn{7}{|l|}{ Smoking § } \\
\hline Currently Smokes & $8(5-12)$ & $11(6-17)$ & $7(3-10)$ & $4(1-7)$ & $10(8-11)$ & $13(13-14)$ \\
\hline Quit Smoking & $19(14-23)$ & $8(4-12)$ & $8(5-12)$ & $10(6-15)$ & $18(16-20)$ & $24(23-25)$ \\
\hline Never Smoked Regularly & $73(67-79)$ & $81(74-87)$ & $85(80-90)$ & $86(80-91)$ & $73(70-75)$ & $63(62-64)$ \\
\hline Ever told had diabetes (excludes gestational)+§ & $15(9-20)$ & $7(4-10)$ & $7(3-11)^{\star}$ & $9(4-14)$ & $17(15-19)$ & $8(8-9)$ \\
\hline
\end{tabular}

Source: California Health Interview Survey, 2014-2017

Notes: * Statistically unstable - coefficient of variation $>0.3, \S$ Age adjusted, $\ddagger$ Estimate suppressed per California Health Interview Survey guidelines, $†$ Data not available for 2014. Estimate calculated using 2015-2017 data. 
EXHIBIT 3 (table)

Caption: Proportion country of birth by language spoken in medical visit, California 2014-2017

Source: California Health Interview Survey, 2014-2017

Notes: * Statistically unstable - Coefficient of Variation $>0.3$ 


\begin{tabular}{|c|c|c|c|c|c|c|c|c|}
\hline & $\begin{array}{l}\text { United } \\
\text { States }\end{array}$ & Philippines & Vietnam & China & India & Korea & Mexico & $\begin{array}{l}\text { Other } \\
\text { Country }\end{array}$ \\
\hline \multicolumn{9}{|l|}{ Row percent } \\
\hline English & 78 (78-79) & $3(2-3)$ & $1(1-1)$ & $1(1-1)$ & $1(1-2)$ & $0(0-1)$ & $6(6-7)$ & $9(8-10)$ \\
\hline Tagalog & & $\begin{array}{l}96(88- \\
100)\end{array}$ & & & & & & \\
\hline Vietnamese & $2(0-4)^{\star}$ & & $96(92-100)$ & & & & & \\
\hline Mandarin & $4(0-8)^{\star}$ & & $2(0-3)^{\star \star}$ & $\begin{array}{l}70(59- \\
80)\end{array}$ & & & & $22(13-32)$ \\
\hline Cantonese & & & $8(0-26)^{\star \star}$ & $85(66-100)$ & & & & $6(0-14)^{\star}$ \\
\hline $\begin{array}{l}\text { Asian Indian } \\
\text { Languages }\end{array}$ & & & & & $80(49-100)$ & & & $14(0-42)^{\star}$ \\
\hline Korean & & & & & & 99 (96- & & \\
\hline Spanish & $4(3-5)$ & & & & & & $\begin{array}{l}78(75- \\
81)\end{array}$ & $19(16-21)$ \\
\hline
\end{tabular}

\begin{tabular}{|c|c|c|c|c|c|c|c|c|}
\hline Column percent & & & & & & & & \\
\hline English & 99 (99-99) & 91 (87-95) & $\begin{array}{l}41(31- \\
50)\end{array}$ & $\begin{array}{l}52(45- \\
60)\end{array}$ & $\begin{array}{l}96(94- \\
99)\end{array}$ & $\begin{array}{l}52(41- \\
63)\end{array}$ & $\begin{array}{l}38(36- \\
41)\end{array}$ & 76 (72-79) \\
\hline Tagalog & & $8(4-12)$ & & & & & & \\
\hline Vietnamese & & & $\begin{array}{l}55(46- \\
63)\end{array}$ & & & & & \\
\hline Mandarin & & & $2(0-7)^{\star \star}$ & $\begin{array}{l}30(23- \\
36)\end{array}$ & & & & $2(1-3)$ \\
\hline Cantonese & & & & $\begin{array}{l}17(11- \\
22)\end{array}$ & & & & \\
\hline $\begin{array}{l}\text { Asian Indian } \\
\text { Languages }\end{array}$ & & & & & $3(1-6)^{\star}$ & & & \\
\hline Korean & & & & & & $\begin{array}{l}47(36- \\
59)\end{array}$ & & \\
\hline Spanish & & & & & & & $\begin{array}{l}60(58- \\
63)\end{array}$ & $20(17-23)$ \\
\hline
\end{tabular}

EXHIBIT 4 (table)

Caption: Language at medical visit by nativity, California 2014-2017 


\begin{tabular}{|c|c|c|c|}
\hline \multicolumn{2}{|r|}{ Non-US-born } & \multicolumn{2}{|l|}{ US-born } \\
\hline Non-English & $3,509,456$ & 128,524 & $3,637,980$ \\
\hline \multirow[t]{6}{*}{ English } & $4,839,626$ & $17,281,183$ & $22,120,809$ \\
\hline & $8,349,082$ & $17,409,707$ & $25,758,789$ \\
\hline & Sensitivity & $42 \%$ & \\
\hline & Specificity & $99 \%$ & \\
\hline & Positive predictive value & $96 \%$ & \\
\hline & Negative predictive value & $78 \%$ & \\
\hline
\end{tabular}

Source: California Health Interview Survey, 2014-2017

\section{References}

1. World Health Organization (WHO). Global Tuberculosis Report. 2018.

2. Talwar A, Tsang CA, Price SF, Pratt RH, Walker WL, Schmit KM, et al. Tuberculosis - United States, 2018. Am J Transplant. 2019;19(5):1582-8.

3. Centers for Disease Control and Prevention (CDC). Reported Tuberculosis in the United States, 2017. 2018.

4. Menzies NA, Cohen T, Hill AN, Yaesoubi R, Galer K, Wolf E, et al. Prospects for Tuberculosis Elimination in the United States: Results of a Transmission Dynamic Model. Am J Epidemiol. 2018;187(9):2011-20.

5. Goodell AJ, Shete PB, Vreman R, McCabe D, Porco TC, Barry PM, et al. Outlook for tuberculosis elimination in California: An individual-based stochastic model. PLoS One. 2019;14(4):e0214532.

6. France AM, Grant J, Kammerer JS, Navin TR. A field-validated approach using surveillance and genotyping data to estimate tuberculosis attributable to recent transmission in the United States. Am J Epidemiol. 2015;182(9):799-807.

7. California Tuberculosis Elimination Advisory Committee. California Tuberculosis Elimination Plan 2016-2020. Richmond, CA; 2016 July 2016.

8. California Department of Public Health TB Control Branch. Report on Tuberculosis in California, 2017,. 2018.

9. Kahwati LC, Feltner C, Halpern M, Woodell CL, Boland E, Amick HR, et al. Primary Care Screening and Treatment for Latent Tuberculosis Infection in Adults: Evidence Report and Systematic Review for the US Preventive Services Task Force. JAMA. 2016;316(9):970-83. 
10. California Health Interview Survey. Los Angeles, CA: UCLA Center for Health Policy Research.

11. California Health Interveiw Survey. CHIS 2017 Methodology Series: Report 1 - Sample Design. Los Angeles, CA: UCLA Center for Health Policy Research; 2018.

12. California Health Interveiw Survey. CHIS 2017 Adult Questionnaire. Los Angeles, CA2018.

13. Cain KP, Benoit SR, Winston CA, Mac Kenzie WR. Tuberculosis among foreign-born persons in the United States. JAMA. 2008;300(4):405-12.

14. Readhead A, Chang AH, Ghosh JK, Sorvillo F, Detels R, Higashi J. Challenges and solutions to estimating tuberculosis disease incidence by country of birth in Los Angeles County. PLoS One. 2018;13(12):e0209051.

15. U.S. Census Bureau. Annual Estimates of the Resident Population for Selected Age Groups by Sex for the United States, States, Counties and Puerto Rico Commonwealth and Municipios: April 1, 2010 to July 1, 2017. 2018.

16. Olson NA, Davidow AL, Winston CA, Chen MP, Gazmararian JA, Katz DJ. A national study of socioeconomic status and tuberculosis rates by country of birth, United States, 1996-2005. BMC Public Health. 2012;12:365.

17. Bakhash YR, Adam; Flood, Jennifer; Watt, James; Barry, Pennan. Association of Area-Based Socioeconomic Measures With Tuberculosis Incidence Rates - California, 2012-2016. National Tuberculosis Controllers Association; April 23, 2019; Atlanta, GA2019. 